\title{
Uncertainty Costs Optimization of Residential Solar Generators Considering Intraday Markets
}

\author{
Julian Garcia-Guarin (1), David Alvarez (1) and Sergio Rivera *(1) \\ Electrical Engineering, Universidad Nacional de Colombia, Bogotá 110111, Colombia; \\ pjgarciag@unal.edu.co (J.G.-G.); dlalvareza@unal.edu.co (D.A.) \\ * Correspondence: srriverar@unal.edu.co; Tel.: +56-3204632806
}

Citation: Garcia-Guarin, J.; Alvarez, D.; Rivera, S. Uncertainty Costs Optimization of Residential Solar Generators Considering Intraday Markets. Electronics 2021, 10, 2826. https://doi.org/10.3390/ electronics10222826

Academic Editors: Nebojša Raičević, Vasilija Šarac and Marinko Barukčić

Received: 13 October 2021

Accepted: 15 November 2021

Published: 17 November 2021

Publisher's Note: MDPI stays neutral with regard to jurisdictional claims in published maps and institutional affiliations.

Copyright: (c) 2021 by the authors. Licensee MDPI, Basel, Switzerland. This article is an open access article distributed under the terms and conditions of the Creative Commons Attribution (CC BY) license (https:/ / creativecommons.org/licenses/by/ $4.0 /)$.

\begin{abstract}
The uncertainty of solar generation and the bull market are unavoidable in energy dispatch The purpose of this research is to validate an uncertainty cost function of residential photovoltaic energy in a real microgrid by varying the number of auctions in intraday markets. Therefore, the following procedure is proposed. First, the variability of photovoltaic generation is quantified through Monte Carlo simulations. Second, a statistical function calculates the variability costs of photovoltaic generation. Third, the uncertainty costs are estimated by varying intraday auction markets. Other complementary services are added to the network, such as battery exchange stations for electric vehicles, demand response loads, market power restrictions, and energy storage systems, which are estimated as total costs in an index ranking. The total costs are optimized in a benchmark microgrid and take complimentary services as a black box. Only the uncertainty costs of residential solar generators are discriminated. The main findings were that (1) the uncertainty costs have an error of less than $0.0168 \%$ compared to the Monte Carlo simulations and that (2) the uncertainty costs of solar generation are reduced with a decreasing trend to a more significant number of auction markets in intraday markets.
\end{abstract}

Keywords: electric markets; photovoltaic generation; Monte Carlo simulations

\section{Introduction}

The greater diffusion of renewable energies mitigates the environmental deterioration caused by greenhouse gases due to conventional electricity generation (Gen) [1]. Power microgrids (MGs)are complex because they face uncertainties such as demand forecasts, electric vehicles (EVs), battery swapping stations (BSSs), market price (MP) variability, and renewable energy forecasts [2-7]. Gen is strongly influenced by the variability of electricity market (EM) prices, which seek to minimize operating costs using energy sources such as the solar power [8]. Furthermore, pivotal agents and monopolies should be reduced because they produce market power. Traditionally, the Herfindahl Hirschman index and the Residual Supply Index have been used to monitor EMs [9].

The prediction of photovoltaic (PV) energy has been extensively studied with Monte Carlo simulations [8]. However, the lack of reliable information on solar Gen makes energy delivery less efficient. Weather conditions such as unpredictable winds prevent forecasts from being accurate. In such a scenario, uncertainty is inherent and cannot be eliminated in planning [8]. Additionally, energy is available in Ems, where agents can buy and sell power [10]. Intraday markets (IMs) present an additional complexity that should be responsible for mismatches in scheduling on the day of operation. These imbalances are produced by changes in the forecasts of the load or PV Gen [11].

The regularization of the electric generators that are involved in energy dispatch must be studied in more detail. The user is given reliability, and study on the reserves that allow absorbing market volatilities is imperative. The literature suggests planning with multiple agents to reduce greenhouse gas costs, separately evaluating operating 
expenses and revenues obtained in markets, and assessing the demand curve $[10,12,13]$. Another approach takes price information from a real EM to conduct energy dispatch planning [14]. However, the adequate number of IM auctions and their relationship with (PV) Gen remains undefined [11].

The main objective of this research is to evaluate the various residential solar Gen curves of an electrical MG, which is the basis for energy dispatch [15]. Gen overestimation and underestimation deviations must be adjusted using a statistical function [8]. The variations are quantified and compared with Monte Carlo simulations [16]. Once the uncertainty costs (UCs) are estimated, UCs due to deviations in the energy dispatch of the MG are evaluated [8]. The solution strategy uses the variable neighbourhood searchdifferential evolutionary particle swarm optimization (VNS-DEEPSO) algorithm in two stages: the first one optimizes the economic benefits of the MG, and the second one optimizes the IMs [17]. This algorithm was selected due to its high performance in smart MG optimization problems [18].

The evaluations of the revenues from solar Gen were conducted by taking 500 representative scenarios out of 5000 [14]. The costs were collated with the results obtained from the Monte Carlo simulations, yielding an error between $7 \times 10^{-5} \%$ and $0.0168 \%$ for one day of operation. The prices of uncertainty are evaluated by varying the IM auctions. It is ascertained that with greater number of auctions, the imbalances in the scheduling of solar Gen decrease.

This article presents the following structure: In Section 2, works related to the present investigation are compared. Section 3 presents the mathematical formulation of the UCs and the formulation of the objective cost function of the MG. Section 4 offers the case study, Section 5 shows the results, and Section 6 outlines the main conclusions of this investigation.

\section{State of the Art}

In the literature, studies on smart MGs that optimize resources are reviewed [19]. Most of the works propose the improvement of the services of the steady demand and the generators $[6,19,20]$ so that users can participate in demand response (DR) programs [21]. They can also collaborate with flexible load management by improving their consumption habits $[15,22,23]$. Energy storage systems (ESSs) promise to provide further flexibility to stakeholders, who can buy off-peak energy hours and sell it during peak hours $[4,10,17,23]$. EMs benefit from previous integration that also facilitates the penetration of renewable resources such as solar energy [8,15]. In the case of IMs, the auction numbers play an essential role in the planning of energy dispatch [11].

This research focuses on the comparison of the storage systems (SSs) with batteries, IMs, and solar energy UCs (SEUCs), as shown in Table 1. SSs with batteries include different models of ESSs and residential EVs (REVs). The models in the table are listed below. Model 1 consists of an aggregator that performs transactions between ESSs and MPs, while Model 6 appraises the interaction between providers and users [4]. Model 2 evaluates the revenues from buying and selling in the market [6]. Model 3 suggests evaluating consumption patterns and their interaction with electricity prices [24]. Model 4 shows the incentives of IMs for intermittent generators, which can participate through meritocracy [25-31]. Model 5 estimates deviations in the energy dispatch due to EV uncertainty [8]. Model 7 encourages the participation of programs with DR; in addition, Model 8 includes IMs $[19,20]$. 
Table 1. Review of electrical MGs.

\begin{tabular}{ccccc}
\hline No & SS & IM & SEUC & Comments \\
\hline 1 & Yes & No & No & MG with RS, REV, MP, DR, ESS, and Gen [4] \\
2 & No & No & No & Include DR and Gen [6] \\
3 & No & No & No & Include ESS and Gen [24] \\
4 & No & Yes & No & Include DR and Gen [25] \\
5 & No & No & Yes & Include REV and Gen [8] \\
6 & Yes & No & No & Smart grid with DR [29] \\
7 & No & No & No & Include DR and Gen [19] \\
8 & No & Yes & No & Include DR and Gen [20] \\
9 & Yes & No & No & Include ESS, demand, and Gen [26] \\
10 & Yes & No & No & Include DR, Gen, ESS, and EV [22] \\
11 & No & No & No & Include DR and Gen [21] \\
12 & No & No & No & Include RS, MP, Gen, demand, and ESS [27] \\
13 & Yes & No & No & Include RS, Gen, ESS, and REV [30] \\
14 & No & No & No & Include DR, Gen, ESS, and REV [31] \\
15 & No & No & No & Include DR, Gen, and ESS [12] \\
16 & No & No & No & Include DR, Gen, and ESS [32] \\
17 & Yes & Yes & Yes & MG with RS, REV, MP, DR, ESS, REV, BSS, and \\
& & & & Gen(This proposal belongs to this paper) \\
\hline
\end{tabular}

Model 9 uses ESSs and predicts demand and Gen [26]. Model 10 enables load reduction [22]. Model 11 encourages competitiveness in EMs between DR and Gen [22]. Model 12 combines renewable sources (RSs), such as a PV panel and ESSs, to reduce $\mathrm{CO}_{2}$ emissions [27]. Model 13 schedules the commissioning of thermal power plants, which reduces gas emissions and operating costs. Additional vehicles, wind and photovoltaic generators, and ESSs are connected to the grid. In addition, Model 14 schedules the load when faced with uncertainty regarding the future price. Model 15 reduces both costs and environmental emissions by using hybrid systems with batteries and wind and solar generators. Model 16 formulates distributed energy resources, with the energy reserve capacity and coordination of the operation with renewable resources and cogeneration. Model 17, which is the model proposed in this research, turns out to be the most complete. It has an aggregator managing the MG's resources, including RS, REV, MP, IM, DR, ESS, REV, BSS, and Gen $[5,7,14,28]$. In addition, the MG has restrictions that prevent the appearance of monopolies, pivotal agents, and a minimum supply of demand. [9,13]. Furthermore, the mathematical formulation of the uncertainty caused by deviations in solar energy dispatch is stated $[8,15]$. The costs of the MG are optimized using the VNS-DEEPSO algorithm, which presents the best performance in a similar MG $[17,18]$.

\section{Mathematical Formulation}

The mathematical models are presented in two sections. The first section establishes the UCs for solar Gen. The second section formulates the objective function for the MG.

\subsection{Uncertainty Costs of Photovoltaic Generation}

The irradiance distribution $(G)$ is represented using a probability function $\left(f_{G}\right)$, where the parameter $(\lambda)$ is the mean, and the parameter $(\beta)$ is the standard deviation [33]. The distribution for intraday solar radiation curves can be adjusted as follows.

$$
f_{G}(G)=\frac{1}{G \beta \sqrt{2 \pi}} \cdot e^{-\frac{(\ln (G)-\lambda)^{2}}{2 \beta^{2}}} ; 0<G<\infty
$$


In solar panels, the power that is generated depends on the reference irradiance $R_{C}$. The irradiance can be represented by quadratic or linear behavior, as depicted below [33].

$$
f_{G} W_{P V}(G)=\left\{\begin{array}{c}
W_{P V_{r}} \cdot \frac{G^{2}}{G_{r} R_{C}}, 0<G<R_{C} \\
W_{P V_{r}} \cdot \frac{G}{G_{r}}, G>R_{C}
\end{array}\right.
$$

The overestimation $C_{P V, 0, i}$ or underestimation $C_{P V, u, i}$ represents the deviations in the binding dispatch and IMs. The variable $W_{P V, i}$ represents $P V$ generators $i$ and the available power, while the power programmed by the aggregator is represented by $W_{P V, s, i}$.

$$
U C F=C_{P V, u, i}\left(W_{P V, s, i}-W_{P V, i}\right)+C_{P V, o, i}\left(W_{P V, i}-W_{P V, s, i}\right)
$$

\subsection{Objective Function of Microgrid}

The smart MG is represented in Figure 1, which has a bidirectional flow of information. The following tasks are undertaken: buying and selling energy in IMs, charging and discharging ESSs, charging and discharging batteries from a BSS, and charging and discharging EVs. Other elements that comprise the MG are the distributed generators (DGs) and load with DR $[5,7,14,28]$. In addition, the smart MG considers restrictions such as the Herfindahl-Hirschman concentration index and the index of the three most prominent bidders to avoid monopolies and pivotal agents [9]. There is also the demand welfare, which ensures a minimum consumption of the demand [13].

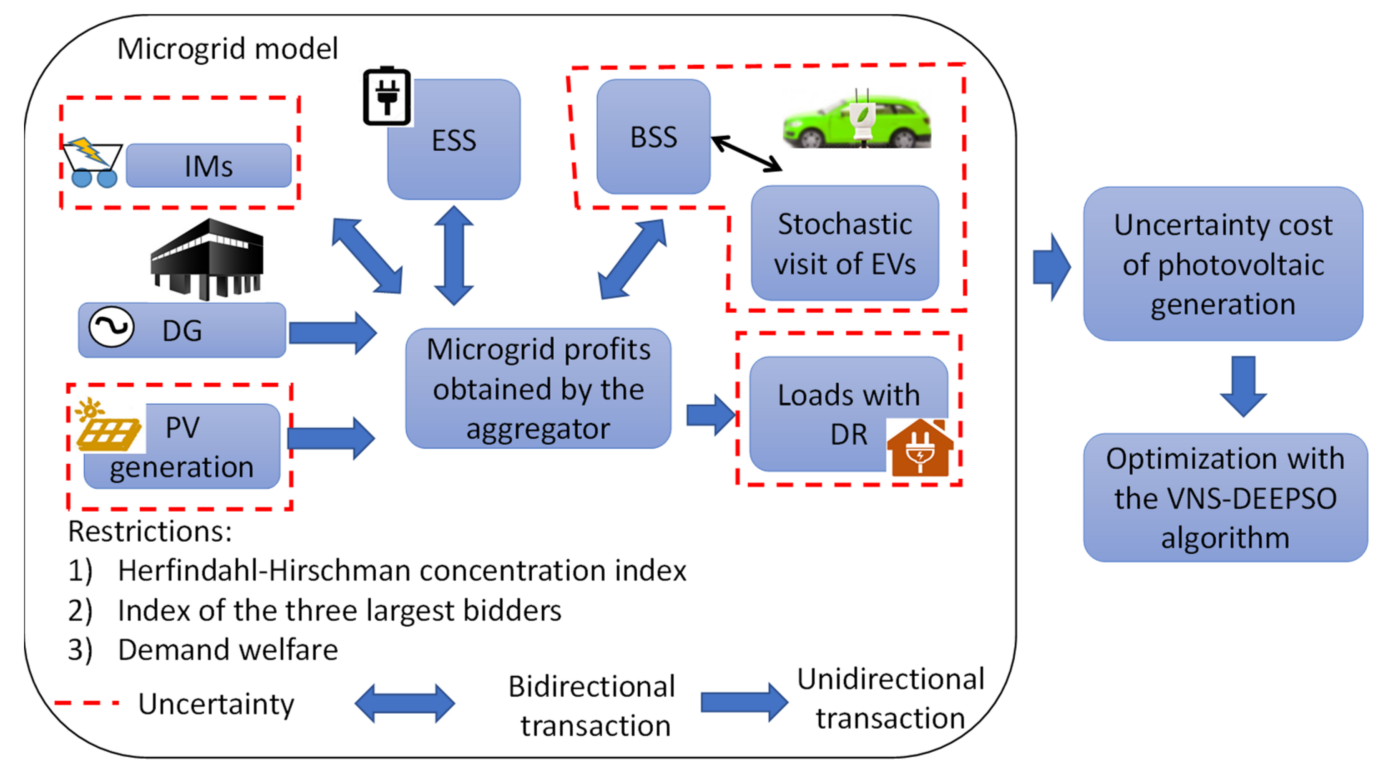

Figure 1. Structure of the electrical microgrid.

The MG model operates in a black box. Information is taken from a real MG, in which the input variables are calculated, and the MG model calculates the benefits obtained as presented below [14]. The profits of the network are represented by $\mathrm{P}$, periods are represented by $t$, scenarios are represented by $s$, the probability of the occurrence of each scenario is characterized by $\mathrm{Pr}, \mathrm{Ns}$ is the maximum number of scenarios, and $\mathrm{T}$ is the maximum number of periods.

$$
M G_{\text {Total }}^{\text {Intraday }+1}=\sum_{s=1}^{N_{s}}\left(\sum_{t=1}^{T=T i} P_{(t, s)}+\sum_{t=T i+1}^{T=2 T i} P_{(t, s)}+\sum_{t=i T i+1}^{T=24} P_{(t, s)}\right) \cdot \operatorname{Pr}(s)
$$


The deviations in the dispatch of solar energy will appear in each of the intraday periods. The UCs are calculated for each period, where $N_{P V}$ represents the maximum number of PV Gen units.

$$
\begin{gathered}
\sum_{s=1}^{N_{s}}\left(\sum_{t=1}^{T=T i}\left(\sum_{j=1}^{N_{P V}} C_{P V, u, j u}\left(W_{P V, s, i}-W_{P V, i}\right)\right)+\ldots\right. \\
\ldots \sum_{t=T i+1}^{T=2 T i}\left(\sum_{j=1}^{N_{P V}} C_{P V, u, j u}\left(W_{P V, s, i}-W_{P V, i}\right)\right)+\ldots \\
\quad \ldots+\sum_{t=i T i+1}^{T=24}\left(\sum_{j=1}^{N_{P V}} C_{P V, u, j u}\left(W_{P V, s, i}-W_{P V, i}\right)\right)+\ldots \\
\ldots+\sum_{t=1}^{T=T i}\left(\sum_{j=1}^{N_{P V}} C_{P V, o, j u}\left(W_{P V, i}-W_{P V, s, i}\right)\right)+\ldots \\
\ldots \sum_{t=T i+1}^{T=2 T i}\left(\sum_{j=1}^{N_{P V}} C_{P V, o, j u}\left(W_{P V, i}-W_{P V, s, i}\right)\right)+\ldots \\
\left.\ldots+\sum_{t=i T i+1}^{T=24}\left(\sum_{j=1}^{N_{P V}} C_{P V, o, j u}\left(W_{P V, i}-W_{P V, s, i}\right)\right)\right) \\
\{T i, 2 T i, \ldots, 24\} \in \mathbb{Z}
\end{gathered}
$$

The objective function is defined as minimizing the costs of uncertainty for the dispatch of solar energy minus the benefits obtained in the MG, which is optimized by using the VNS-DEEPSO algorithm.

$$
\text { minimize } Z_{\text {Total }}^{\text {Intraday }+1}=U C_{\text {Total }}^{\text {Intraday }+1}-M G_{\text {Total }}^{\text {Intraday }+1}
$$

\section{Case Study Presentation}

The case study is presented in two sections. The first section shows the statistical data used to evaluate the costs of uncertainty, and in the second one, the MG is given.

\subsection{Residential Solar Generators}

The power that is generated daily is taken from [14], where the energy for residential solar panels is considered. Figure 2 shows the power supply for 500 representative scenarios.

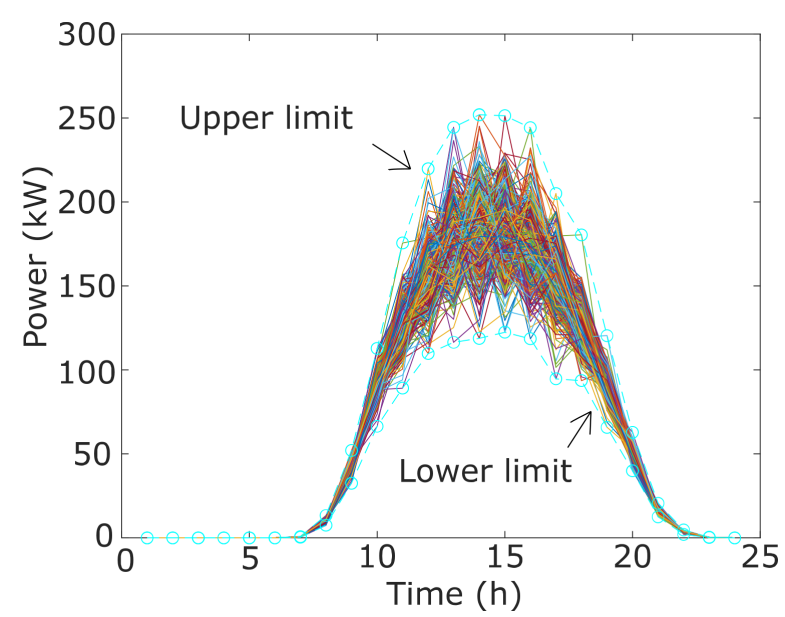

Figure 2. Residential PV generators in $24 \mathrm{~h}$, data from [14]. 
The UC function must be validated using Monte Carlo simulations with which random irradiance values are obtained by assuming the proportionality between the irradiance and the generated power. Solar radiation parameters are considered according to solar radiation distribution frequency functions, as shown in Table 2 [34]. The penalties for overestimation and underestimation are considered [8].

Table 2. Solar generation parameter, data from [34].

\begin{tabular}{ccc}
\hline Symbol & Parameter & Value \\
\hline$W_{P V r}$ & PV Gen source $(\mathrm{MW})$ & 100 \\
$G_{r}$ & Nominal irradiance $\left(\mathrm{W} / \mathrm{m}^{2}\right)$ & 775 \\
$R_{C}$ & Irradiance of reference & 116 \\
$W_{P V, \infty}$ & Maximum power Gen $(\mathrm{MW})$ & 150 \\
$N$ & Number of iterations & 100,000 \\
$W_{P V, s, i}$ & Scheduled PV Gen (MW) & 100 \\
$C_{P V, u, i}$ & Penalty for underestimation & 300 \\
$C_{P V, o, i}$ & (USD/MW) & 700 \\
\hline
\end{tabular}

The solar radiation values in Figure 2 are the basis for calculating the mean and standard deviation of each hour. The obtained values are summarized in Tables 3 and 4 .

Table 3. Mean and standard deviation between 8 and $14 \mathrm{~h}$.

\begin{tabular}{cccccccc}
\hline Symbol & $\mathbf{8}$ & $\mathbf{9}$ & $\mathbf{1 0}$ & $\mathbf{1 1}$ & $\mathbf{1 2}$ & $\mathbf{1 3}$ & $\mathbf{1 4}$ \\
\hline$\beta$ & 0.0965 & 0.0710 & 0.0673 & 0.0887 & 0.1030 & 0.1069 & 0.1121 \\
$\lambda$ & 2.3059 & 3.7685 & 4.4929 & 4.8512 & 5.0494 & 5.1577 & 5.2085 \\
\hline
\end{tabular}

Table 4. Mean and standard deviation between 15 and $21 \mathrm{~h}$.

\begin{tabular}{cccccccc}
\hline Symbol & $\mathbf{1 5}$ & $\mathbf{1 6}$ & $\mathbf{1 7}$ & $\mathbf{1 8}$ & $\mathbf{1 9}$ & $\mathbf{2 0}$ & $\mathbf{2 1}$ \\
\hline$\beta$ & 0.0965 & 0.0710 & 0.0673 & 0.0887 & 0.1030 & 0.1069 & 0.1121 \\
$\lambda$ & 2.3059 & 3.7685 & 4.4929 & 4.8512 & 5.0494 & 5.1577 & 5.2085 \\
\hline
\end{tabular}

\subsection{Objective Function of Microgrid}

MG is located in Portugal and comprises 17 solar Gen units, 5 dispatchable units, 34 REVs, 2 ESSs, an external electricity service provider, and 90 users who actively participate in DR programs $[35,36]$. The distribution transformer is $160 \mathrm{kVA}$ and connects to a medium and low voltage line of $30 \mathrm{kV} / 400 \mathrm{~V}-230 \mathrm{~V}$ [37]. The five dispatchable units comprise four DGs and an external solar generator. The transformer is connected to 25 buses [37]. Additionally, MG can transfer energy with intraday markets [11]. It also has penalties for costs of uncertainty in the Gen of solar energy, market power restrictions, and constraints on the minimum supply of energy for demand $[9,13,15]$. MG is optimized using the VNSDEEPSO algorithm, which improves MG in the first stage and MIs in the second stage, as shown in Figure $3[17,18]$. 


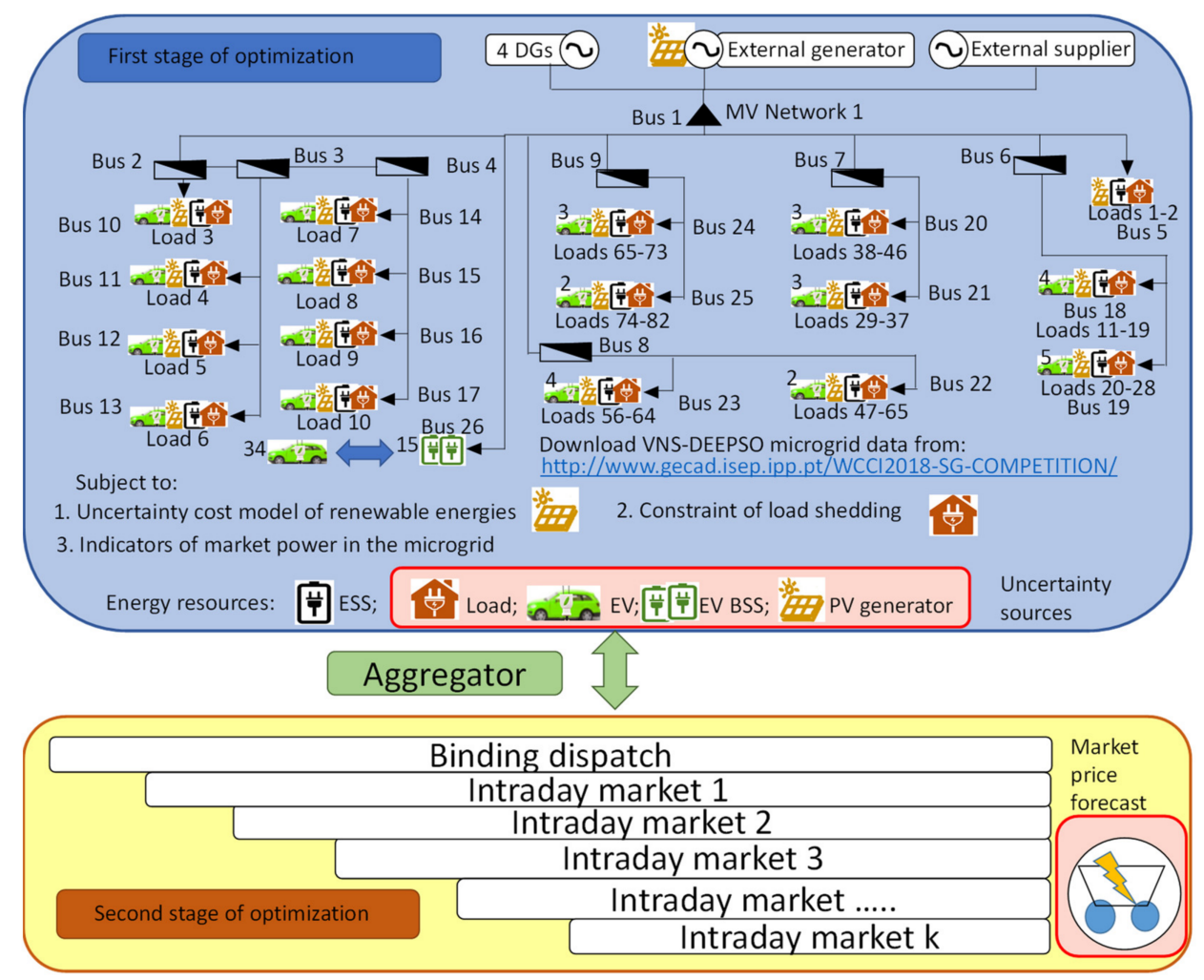

Figure 3. Solar generators in the electrical microgrid [14].

\section{Results and Discussion}

The results are presented in two sections. In the first section, the UCs for residential solar energy Gen are validated, while in the second one, the UCs are estimated by varying the IMs of the MG.

\subsection{Uncertainty Costs with Residential Solar Generators}

The validation uses Monte Carlo simulations to determine the histograms of irradiance and solar power generated with the underestimated and overestimated costs of solar radiation, as shown in Figure 4.

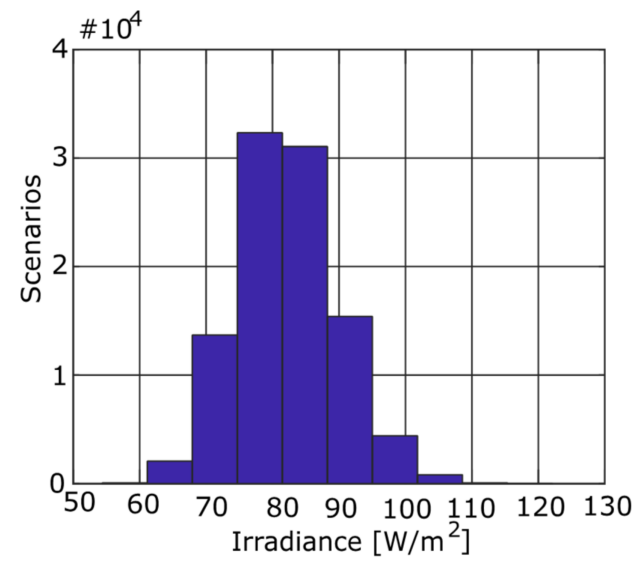

(a)

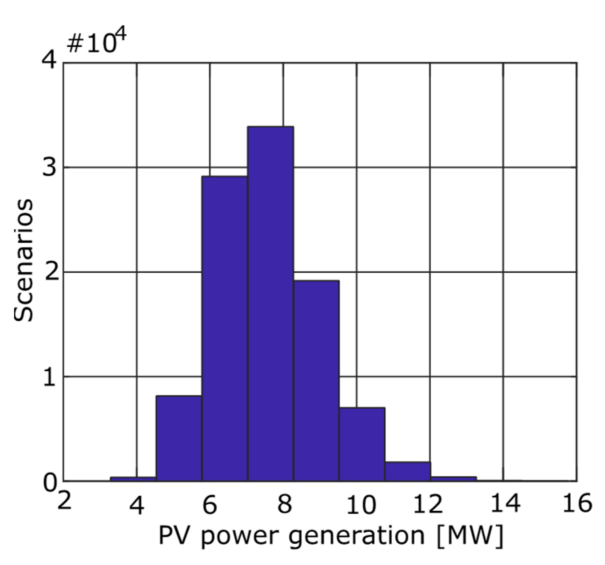

(b)

Figure 4. Histograms of (a) irradiance and (b) solar power generated. (\# means $10^{4}$ ).

Penalties due to UCs are determined, and UCs are calculated while solar Gen varies (Figure 5). 


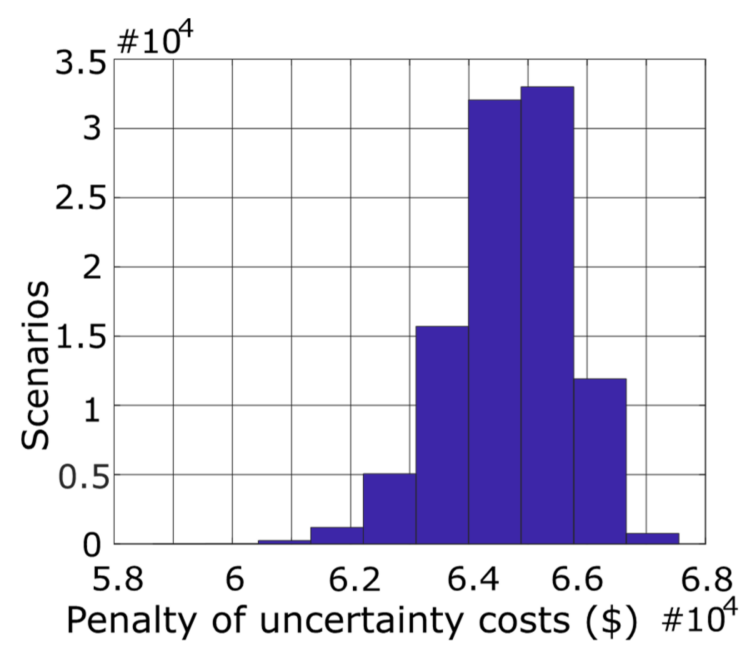

(a)

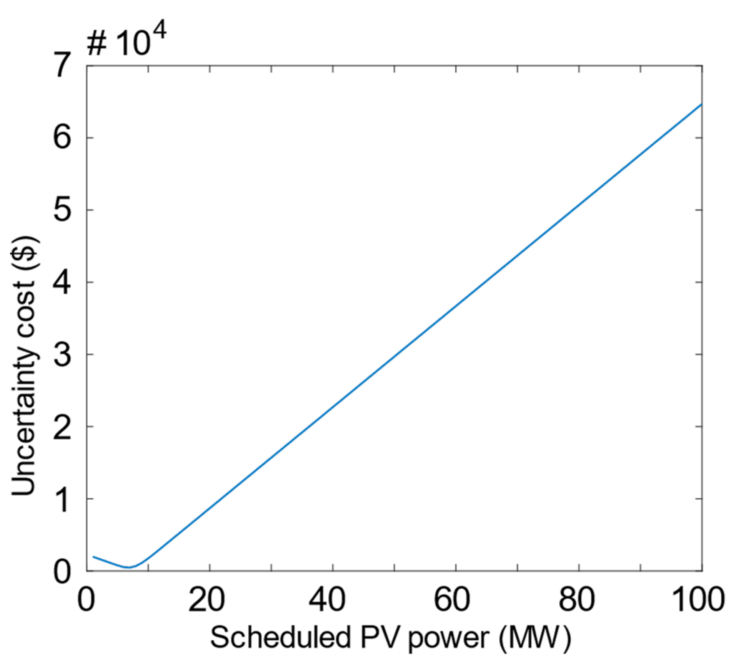

(b)

Figure 5. Monte Carlo simulations for (a) UC function histogram and (b) evaluation of UCs by varying solar power. (\# means $\left.10^{4}\right)$.

Finally, the UCs are evaluated for each hour using Monte Carlo simulations and the UC function. In the Monte Carlo simulations, the value is obtained with the average of the estimated values $M C_{P V}$ [38]. The costs for underestimation and overestimation are used [33] as shown below.

$$
A C_{P V}=E\left[C_{P V, u, i}\left(W_{P V, s, i}, W_{P V, i}\right)\right]+E\left[C_{P V, u, i}\left(W_{P V, o, i}, W_{P V, i}\right)\right]
$$

The estimated error when evaluating the Monte Carlo functions and the UC function is summarized in Tables 5 and 6 . The error is in the range between $7 \times 10^{-5} \%$ and $0.0168 \%$. This research differs from previous works in which the uncertainty costs of renewable energies per day had been evaluated; in this research, a set of intraday evaluations per hour is carried out. For comparative purposes, the highest error reported in each research is taken, in which the error of $0.0168 \%$ is more exact than the errors obtained for $0.0615 \%$ from [39], $0.0343 \%$ from [16], and $0.072 \%$ from [33]. This means that this investigation contains the error closest to zero.

Table 5. The estimated error between 8 and $14 \mathrm{~h}$.

\begin{tabular}{cccccccc}
\hline Symbol & $\mathbf{8}$ & $\mathbf{9}$ & $\mathbf{1 0}$ & $\mathbf{1 1}$ & $\mathbf{1 2}$ & $\mathbf{1 3}$ & $\mathbf{1 4}$ \\
\hline$M C_{P V}(\$)$ & 64,698 & 68,525 & 63,725 & 58,465 & 55,843 & 54,220 & 53,375 \\
$A C_{P V}(\$)$ & 64,695 & 68,524 & 63,723 & 58,460 & 55,842 & 54,215 & 53,383 \\
e $(\$)$ & 0.0049 & $4 \times 10^{-4}$ & 0.0026 & 0.0099 & 0.0027 & 0.0088 & 0.0151 \\
\hline
\end{tabular}

Table 6. The estimated error between 15 and $21 \mathrm{~h}$.

\begin{tabular}{cccccccc}
\hline Symbol & $\mathbf{1 5}$ & $\mathbf{1 6}$ & $\mathbf{1 7}$ & $\mathbf{1 8}$ & $\mathbf{1 9}$ & $\mathbf{2 0}$ & $\mathbf{2 1}$ \\
\hline$M C_{P V}(\$)$ & 69,920 & 68,526 & 63,726 & 58,465 & 55,844 & 54,216 & 53,374 \\
$A C_{P V}(\$)$ & 69,920 & 68,524 & 63,723 & 58,460 & 55,842 & 54,215 & 53,383 \\
$\mathrm{e}(\$)$ & $7 \times 10^{-5}$ & 0.002 & 0.0047 & 0.0091 & 0.0041 & 0.0022 & 0.0168 \\
\hline
\end{tabular}

\subsection{Uncertainty Costs Varing Intraday Markets in the Microgrid}

The uncertainty from the solar energy dispatch is due to the underestimation and overestimation of the power. The MG model considers the UCs for solar Gen with 2, 3, 4, and 6 IMs. The auctions are taken in symmetrical times; for example, in the case of three intraday markets, the auctions are conducted every $8 \mathrm{~h}$, as shown in [11]. The uncertainty 
costs due to overrating and underestimating the solar energy dispatch are reduced with a more significant number of intraday markets, as shown in Figure 6.

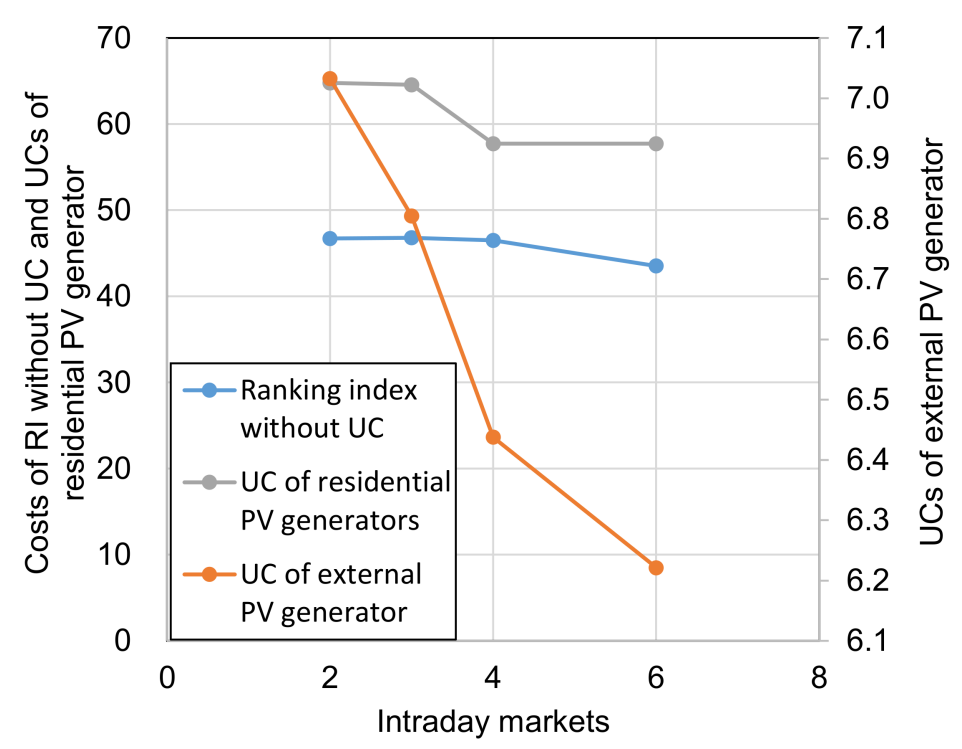

Figure 6. UCs of PV generators varying IMs.

\section{Conclusions}

The uncertainty in energy distribution planning is inevitable and can have minor impacts on the planning of electrical microgrids. This research quantified the uncertainty of the solar generation of an electric microgrid and validated the methodology using Monte Carlo simulations. The relative error of the uncertainty cost estimation function for the solar energy generation obtained values in the range between $7 \times 10^{-5} \%$ and $0.0168 \%$. In addition, the authors evaluated the effect of intraday markets in an optimization case of an electrical microgrid. It was found that the costs of uncertainty for the generation of the solar energy decrease when the number of intraday markets increases, thus considering symmetrical daily auction periods. For example, in the case of three intraday markets, the auctions are carried out every $8 \mathrm{~h}$. The aggregator improved the economic management of the network with a more significant number of intraday markets. Future works should evaluate other sources of clean energy such as micro-hydroelectric plants and wind turbines. Such studies must also assess the effect of the implementation of intraday markets with non-symmetrical daily auction periods on the costs of uncertainty.

Author Contributions: This research was carried out with the following contributions by the authors: conceptualization, D.A. and S.R.; methodology, J.G.-G. supported by Colciencias, Colombia, Call 785 for national doctorates; validation, S.R. and J.G.-G.; formal analysis, D.A.; investigation, J.G.-G.; supervision, D.A. and S.R.; writing —original draft preparation, J.G.-G.; writing—review and editing, D.A. and S.R.; funding acquisition, S.R. All authors have read and agreed to the published version of the manuscript.

Funding: This research received no external funding.

Data Availability Statement: The MG model is available online at: http:/ /www.gecad.isep.ipp.pt/ WCCI2018-SG-COMPETITION/ by the group GECAD—Polytechnic of Porto (access date 16/03/2021).

Conflicts of Interest: The authors declare no conflict of interest.

\section{References}

1. Gharavi, H.; Ghafurian, R. Smart grid: The electric energy system of the future. Proc. IEEE 2011, 9, 913-914.

2. Marzband, M.; Sumper, A.; Domínguez-García, J.L.; Gumara-Ferret, R. Experimental validation of a real time energy management system for microgrids in islanded mode using a local day-ahead electricity market and MINLP. Energy Convers. Manag. 2013, 76, 314-322. [CrossRef] 
3. Garcia, J.; Alvarez, D.; Rivera, S. Ensemble Based Optimization for Electric Demand Forecast: Genetic Programming and Heuristic Algorithms. Rev. Int. Métodos Numér. Cálc. Diseño Ing. 2020, 1, 1-13. [CrossRef]

4. Soares, J.; Fotouhi Ghazvini, M.A.; Borges, N.; Vale, Z. A stochastic model for energy resources management considering demand response in smart grids. Electr. Power Syst. Res. 2017, 143, 599-610. [CrossRef]

5. Garcia-Guarin, J.; Infante, W.; Alvarez, D.; Rivera, S. Scheduling optimization for smart microgrids considering twolevels transactions of electric vehicles and energy markets. J. Phys. Conf. Ser. 2020, 1708, 012019. [CrossRef]

6. Abrishambaf, O.; Faria, P.; Spínola, J.; Vale, Z. An Aggregation Model for Energy Resources Management and Market Negotiations. Adv. Sci. Technol. Eng. Syst. J. 2018, 3, 231-237. [CrossRef]

7. Garcia-Guarin, J.; Infante, W.; Ma, J.; Alvarez, D.; Rivera, S. Optimal Scheduling of Smart Microgrids Considering Electric Vehicle Battery Swapping Stations. Int. J. Electr. Comput. Eng. 2020, 10, 5093-5107.

8. Arévalo, J.; Santos, F.; Rivera, S. Application of Analytical Uncertainty Costs of Solar, Wind and Electric Vehicles in Optimal Power Dispatch. Ingeniería 2017, 22, 324-346. [CrossRef]

9. Garcia-Guarin, J.; Rivera, S.; Trigos, L. Multiobjective optimization of smart grids considering market power. J. Phys. Conf. Ser. 2019, 1409, 012006. [CrossRef]

10. Lezama, F.; Soares, J.; Faia, R.; Pinto, T.; Vale, Z. A New Hybrid-Adaptive Differential Evolution for a Smart Grid Application under Uncertainty. In Proceedings of the 2018 IEEE Congress on Evolutionary Computation, CEC 2018-Proceedings, Rio de Janeiro, Brazil, 8-13 July 2018; pp. 1-8.

11. Garcia-Guarin, J.; Duran-Pinzón, M.; Paez-Arango, J.; Rivera, S. Energy planning for aquaponics production considering intraday markets. Arch. Electr. Eng. 2020, 69, 89-100. [CrossRef]

12. Radhakrishnan, B.M.; Srinivasan, D.; Mehta, R. Fuzzy-Based Multi-Agent System for Distributed Energy Management in Smart Grids. Int. J. Uncertain. Fuzziness Knowl.-Based Syst. 2016, 24, 781-803. [CrossRef]

13. Garcia-Guarin, J.; Alvarez, D.; Bretas, A.; Rivera, S. Schedule Optimization in A Smart Microgrid Considering Demand Response Constraints. Energies 2020, 13, 4567. [CrossRef]

14. Lezama, F.; Soares, J.; Vale, Z.; Rueda, J.; Wagner, M. CEC/GECCO 2019 Competition Evolutionary Computation in Uncertain Environments: A Smart Grid Application. In Proceedings of the 2018 IEEE Congress on Evolutionary Computation, CEC 2018-Proceedings, Rio de Janeiro, Brazil, 8-13 July 2018.

15. Garcia Guarin, J.; Lezama, F.; Soares, J.; Rivera, S. Operation scheduling of smart grids considering stochastic uncertainty modelling. Far East J. Math. Sci. 2019, 1,77-98. [CrossRef]

16. Vargas, S.; Rodriguez, D.; Rivera, S. Mathematical Formulation and Numerical Validation of Uncertainty Costs for Controllable Loads. Rev. Int. Métodos Numéricos Para Cálculo Y Diseño En Ing. 2019, 35, 1-17. [CrossRef]

17. García-Guarín, P.J.; Cantor-López, J.; Cortés-Guerrero, C.; Guzmán-Pardo, M.A.; Rivera, S. Implementación del algoritmo VNS-DEEPSO para el despacho de energía en redes distribuidas inteligentes. INGE CUC 2019, 15, 142-154. [CrossRef]

18. Garcia-Guarin, J.; Rodriguez, D.; Alvarez, D.; Rivera, S.; Cortes, C.; Guzman, A.; Bretas, A.; Aguero, J.R.; Bretas, N. Smart microgrids operation considering a variable neighborhood search: The differential evolutionary particle swarm optimization algorithm. Energies 2019, 12, 3149. [CrossRef]

19. Jadid, S.; Zakariazadeh, A. Energy and reserve scheduling of microgrid using multi-objective optimization. In Proceedings of the 22nd International Conference and Exhibition on Electricity Distribution (CIRED 2013), Stockholm, Sweden, 10-13 June 2013; pp. 631-660.

20. Cecati, C.; Citro, C.; Siano, P. Combined Operations of Renewable Energy Systems and Responsive Demand in a Smart Grid. IEEE Trans. Sustain. Energy 2011, 2, 468-476. [CrossRef]

21. Faria, P.; Soares, T.; Vale, Z.; Morais, H. Distributed generation and demand response dispatch for a virtual power player energy and reserve provision. Renew. Energy 2014, 66, 686-695. [CrossRef]

22. Sousa, T.; Morais, H.; Vale, Z.; Faria, P.; Soares, J. Intelligent Energy Resource Management Considering Vehicle-to-Grid: A Simulated Annealing Approach. IEEE Trans. Smart Grid 2012, 3, 535-542. [CrossRef]

23. Garcia-Guarin, J.; Rivera, S.; Rodriguez, H. Smart grid review: Reality in Colombia and expectations. J. Phys. Conf. Ser. 2019, 1257, 012011. [CrossRef]

24. Tushar, W.; Chai, B.; Yuen, C.; Smith, D.B.; Wood, K.L.; Yang, Z.; Poor, H.V. Three-Party Energy Management with Distributed Energy Resources in Smart Grid. IEEE Trans. Ind. Electron. 2015, 62, 2487-2498. [CrossRef]

25. Zhou, Y.; Wang, C.; Wu, J.; Wang, J.; Cheng, M.; Li, G. Optimal scheduling of aggregated thermostatically controlled loads with renewable generation in the intraday electricity market. Appl. Energy 2017, 188, 456-465. [CrossRef]

26. Matthiss, B.; Momenifarahaniy, A.; Ohnmeissz, K.; Felderx, M. Influence of Demand and Generation Uncertainty on the Operational Efficiency of Smart Grids. In Proceedings of the 7th International IEEE Conference on Renewable Energy Research and Applications, ICRERA 2018, Paris, France, 14-17 October 2018; pp. 751-756.

27. Di Somma, M.; Graditi, G.; Heydarian-Forushani, E.; Shafie-khah, M.; Siano, P. Stochastic optimal scheduling of distributed energy resources with renewables considering economic and environmental aspects. Renew. Energy 2018, 116, 272-287. [CrossRef]

28. Lezama, F.; Soares, J.; Vale, Z.; Rueda, J.; Rivera, S.; Elrich, I. 2017 IEEE competition on modern heuristic optimizers for smart grid operation: Testbeds and results. Swarm Evol. Comput. 2019, 44, 420-427. [CrossRef]

29. Chen, J.; Yang, B.; Guan, X. Optimal demand response scheduling with Stackelberg game approach under load uncertainty for smart grid. IEEE SmartGridComm 2012, 1, 546-551. [CrossRef] 
30. Saber, A.Y.; Venayagamoorthy, G.K. Resource scheduling under uncertainty in a smart grid with renewables and plug-in vehicles. IEEE Syst. J. 2012, 6, 103-109. [CrossRef]

31. Deng, R.; Yang, Z.; Chen, J.; Chow, M.-Y. Load Scheduling With Price Uncertainty and Temporally-Coupled Constraints in Smart Grids. IEEE Trans. Power Syst. 2014, 29, 2823-2834. [CrossRef]

32. Quashie, M.; Marnay, C.; Bouffard, F.; Jóos, G. Optimal planning of microgrid power and operating reserve capacity. Appl. Energy 2018, 210, 1229-1236. [CrossRef]

33. Arevalo, J.C.; Santos, F.; Rivera, S. Uncertainty cost functions for solar photovoltaic generation, wind energy generation, and plug-in electric vehicles: Mathematical expected value and verification by Monte Carlo simulation. Int. J. Power Energy Convers. 2019, 10, 171-207. [CrossRef]

34. Chang, T.P. Investigation on frequency distribution of global radiation using different probability density functions. Int. J. Appl. Sci. Eng. 2010, 8, 99-107.

35. Lezama, F.; Sucar, L.E.; de Cote, E.M.; Soares, J.; Vale, Z. Differential evolution strategies for large-scale energy resource management in smart grids. In Proceedings of the Genetic and Evolutionary Computation Conference Companion-GECCO '17, Berlin, Germany, 15-19 July 2017; pp. 1279-1286. [CrossRef]

36. Soares, J.; Silva, M.; Canizes, B.; Vale, Z. MicroGrid der control including EVs in a residential area. In Proceedings of the 2015 IEEE Eindhoven PowerTech, PowerTech 2015; Institute of Electrical and Electronics Engineers Inc.: Piscataway, NJ, USA, 2015; pp. 1-6.

37. Canizes, B.; Silva, M.; Faria, P.; Ramos, S.; Vale, Z. Resource scheduling in residential microgrids considering energy selling to external players. In Proceedings of the 2015 Clemson University Power Systems Conference, PSC 2015, Clemson, SC, USA, 10-13 March 2015.

38. Wackerly, D.; Mendenhall, W.; Scheaffer, R. Estadística Matemática con Aplicaciones, 7th ed.; Cengage Learning: Santa Fe, Mexico, 2010; ISBN 970-625-016-6.

39. Molina Sanchez, F.S.; Pérez Sichacá, S.J.; Rivera Rodriguez, S.R. Formulación de Funciones de Costo de Incertidumbre en Pequeñas Centrales Hidroeléctricas dentro de una Microgrid. Ing. USBMed 2017, 8, 29-36. [CrossRef] 